\title{
Managing Patent Portfolios-Lean IP Management versus Discount IP Management or Better Few Diamonds than Tons of Coal?
}

\author{
Michael Barth'1, Oliver Baldus² \\ ${ }^{1}$ Eder Schieschke \& Partner mbB, Munich, Germany \\ ${ }^{2}$ Schwarz Baldus PartmbB, Munich, Germany \\ Email: michael.barth@eder-ip.de, baldus@sp-ip.de
}

How to cite this paper: Barth, M. and Baldus, O. (2019) Managing Patent Portfolios-Lean IP Management versus Discount IP Management or Better Few Diamonds than Tons of Coal? American Journal of Industrial and Business Management, 9, 1901-1907. https://doi.org/10.4236/ajibm.2019.910123

Received: September 4, 2019

Accepted: October 13, 2019

Published: October 16, 2019

Copyright $\odot 2019$ by author(s) and Scientific Research Publishing Inc. This work is licensed under the Creative Commons Attribution International License (CC BY 4.0). http://creativecommons.org/licenses/by/4.0/

\begin{abstract}
While traditional Discount IP Management focuses on the economic management of a large number of patents, novel Lean IP Management focuses on a handful of valuable ones. Discount IP Management primarily faces the question of how a high number of patents can be handled cost-effectively. Here, it is important to determine how a large patent portfolio can be obtained at a low cost, with a reduction in patent quality taken into account. Lean IP Management is concerned solely with valuable high-quality patents with the potential for economic benefit. Both, the advantages and disadvantages of these opposing concepts are compared by considering psychological and economic aspects in order to find out which of the concepts is the concept of choice for the success of an enterprise.
\end{abstract}

\section{Keywords}

Lean IP Management, Discount IP Management, Large Patent Portfolio, High Quality Patents, Economic Benefit, Less-Is-More, All-in-One Flat Fee Patent Tank, Patent Water Pistol, Market Potential Domain, Waste Domain

\section{Introduction}

While Discount IP Management focuses on the economic management of a large number of patents, the novel approach of Lean IP Management concentrates on a handful of valuable ones [1]. Application of Discount IP Management allows a high number of patents to be handled cost-effectively. Here, it is important how a large patent portfolio can be obtained at a low cost, with a reduction in patent quality taken into account. 
New Lean IP Management considers only valuable high-quality patents with the potential for economic benefit. Lean IPM focuses solely on the economic benefit and positive-asset creation for an enterprise. According to the Lean IPM doctrine, useless patents are eliminated and creating new useless patents is avoided. The creation of useful patents is greatly demanded since positive assets lead to economic benefit. The more resources saved by elimination and avoidance of useless patents, the more resources can be invested into useful ones, thereby creating financial value. According to Lean IPM, patent applications are concisely drafted to focus on assigning protective rights solely to features of an invention where there is strong market potential [2]; features or definitions lacking market potential are discarded. In doing so, the quality of patents automatically increases.

That is, by following LIPM's core "less is more" approach a company's costs for IP rights can be drastically reduced. Saving costs for patents while raising patent quality always goes hand in hand with economic benefit for an enterprise.

\section{On the Meaning of Discount IP Management}

In the last two decades patent portfolio management in various large companies has changed dramatically with respect to cost. More IP law firms are offering so-called "all-in-one flat fees" for the entire patent application procedure from preparing the application to the granting of the patent. Financial controllers of large companies, which file hundreds of patent applications annually, may view flat fees as manna from heaven from a cost-calculation and transparency standpoint. This is understandable when taking into account the high costs of external patent attorneys, which are usually linked to the time expenditure for each legal case. Since every invention is different and the prosecution procedure up to granting a patent strongly depends on specific circumstances, the costs for every patent prosecution procedure are difficult to calculate. All-in-one flat fees are far simpler to calculate and less likely to lead to unexpected balance-sheet fluctuations.

Moreover, the concept of flat fees is usually offered with the argument that the average price for obtaining a patent is cheaper compared to when a law firm charges its usual time-based fees. This leads to a discount-management mentality, thus herein referred to as "Discount IP Management" (Discount IPM). Discount IPM arises from the wish to hold a high number of granted patents within a calculable range of costs, but often with questionable economic benefit. The questionable benefit consists of a massive decrease in quality of Discount IP patents and the resulting losses in economic market positions against competitors.

In conclusion, Discount IPM allows companies to file a high number of patents within a controllable range of costs every fiscal year.

\section{On the Meaning of Lean IP Management}

Lean IP Management (Lean IPM) is a diametrically opposed new concept to Discount IPM since it focuses on eliminating and avoiding waste and negative 
assets in a company for economic reasons. Lean IPM is borne from the conviction that the majority of existing patents are useless from an economic perspective. It is estimated that up to $90 \%$ do not contribute to the economic benefit of the holders [2] [3]. A patent is deemed useless economically if the holder cannot capitalize on it, either because the monopoly of the patent does not bring any economic benefit, or no third party is interested in using the invention by obtaining a license on the patent or purchasing the patent itself. A useless patent can thus be equated to waste. Furthermore, paying for its maintenance is akin to throwing good money after bad as it transforms into a negative asset. An asset is deemed negative if money is wasted for no economic benefit. Following the principles of lean production, Lean IPM demands such patents be avoided and any already in the portfolio abandoned, thereby dramatically reducing IP costs.

Thus, Lean IPM focuses solely on economic benefit and positive-asset creation for an enterprise. Under the Lean IPM doctrine, useless patents are eliminated and creation of new useless patents is avoided. The creation of useful patents is highly demanded since positive assets lead to economic benefit. The more resources are saved by elimination and avoidance of useless patents, the more resources can be invested into useful patents, thereby increasing financial value. According to Lean IPM, patent applications are concisely drafted to focus on assigning protective rights solely to features of an invention where there is strong market potential [4]; features or definitions lacking market potential are omitted. In doing so, the quality of patents automatically increases.

\section{Comparison between Lean IPM and Discount IPM}

While Discount IPM focuses on the economic mass management of a large number of patents, Lean IPM focuses on a small number of useful ones. Discount IPM considers only how a high number of patents can be handled cost effectively, and disregards the value of each patent. Here, it is important first to determine how a large patent portfolio can be obtained at low cost.

Thereby Discount IPM makes use of IP law firms offering flat fees for the entire prosecution procedure from drafting and filing an application to granting of a patent. The fee is the same for each prosecution procedure, regardless of complexity. Even with the advantage of calculable costs, two psychological aspects cannot be disregarded which lead to a reduction of quality of the granted protective rights.

In most law firms an attorney's income is calculated based on the turnover generated by her/his personal services.

The first psychological aspect arises from individuals always following the path of least effort [5]. A patent attorney may draft a patent application in a way that the patent claims have either a high- or low-level protective scope. To obtain the former, the attorney must invest far more time than for the latter. Higher protective scope has to be defended with greater effort during prosecution proceedings, whereas a patent application with a lower scope is usually granted 
faster. Thus, according to human psychology it is unsurprising that flat fees lead to a protective right with a lower protective scope. However, in reference to Akerlof s market for lemons concept [6], this is not detrimental to the business of law firms offering such services, since due to the specialty and nature of patents, it is not possible to assess the quality of a patent in advance.

The second psychological aspect is in regard to the attorney hierarchy within each law firm. Some attorneys distribute work; others do it. The distributing attorneys will usually perform the distribution to their own benefit. In the case of flat fees, this means they will allocate themselves the work that can be accomplished quickest, and delegate any time-consuming work. As flat fees mean time-consuming work usually leads to lower turnover, the serving attorney will tend to draft patent applications with lower protective scope. Here again, the first psychological aspect takes effect, leading to a race to the bottom with respect to patent quality.

Therefore, both psychological aspects bear the danger that flat fees lead to low-grade protective rights and the patent being a negative asset.

Discount IPM is usually applied if the quantity rather than quality of the protective rights is of greater importance to a company. Here, the company risks valuable resources for a plurality of valueless patents. There may be manifold reasons for this. For example, a large patent portfolio might aid in negotiations with a competitor on cross-transferring or cross-licensing patent rights. However, it would be essential that the protective rights be of sufficient quality.

A company seeking valuable patents with a large protective scope would be better served applying Lean IPM, because a handful of strong patents has far greater economic value than a plurality of low-grade protective rights (one "patent tank" has far greater impact than hundreds of "patent water pistols"). Generally, the savings in financial resources outweigh potential disadvantages with respect to negotiations on cross-transferring or cross-licensing of protective rights with competitors.

The following Table 1 shows a comparison of both concepts.

\section{What Does Michael E. Porter Teach Us in This Respect?}

According to the theory of Michael E. Porter, one of the world's most reputable

Table 1. Comparison between discount IPM and lean IPM.

\begin{tabular}{cc}
\hline Discount IP Management & Lean IP Mangament \\
\hline $\begin{array}{c}\text { large patent portfolio } \\
\text { focus on cost effective handling } \\
\text { calculatable flat-fee expenses }\end{array}$ & small patent portfolio \\
focus on quality of each patent \\
disregarding the patents' quality & expenses by hourly rate \\
high costs for questionable economic benefit & strengthening the economic position due to \\
only high quality patents
\end{tabular}


economists, an enterprise is successful in the market if it attains either cost leadership or quality leadership [7] [8]. Cost leadership means selling lower-priced products in large numbers. Examples include discount supermarket chains, and low-end automobiles sold and produced in larger numbers than luxury models. With quality leadership, success is obtained through the quality of the product. Here, customers must be willing to pay a higher price for higher quality. The quality leader usually does not realize its business volume from selling large numbers of units, but rather from fewer high-quality products.

Discount IPM can be compared to cost leadership and Lean IPM to quality leadership. Nevertheless, this comparison fails in one essential area: An economically valuable patent is usually no more cost-intensive than low-grade protective rights with respect to the drafting of the patent application, granting of the patent and annuities. Put another way, Lean IPM would empower a motorist to drive a luxury car for the same investment as a budget one, i.e. the purchaser comfortably attains a higher goal without higher expense. In a further analogy, Lean IPM would enable a few soldiers armed with AK-47s to defeat an entire army equipped with water pistols.

\section{Comparison of a Lean IP Patent Portfolio with a Discount IP Patent Portfolio}

Application of Lean IPM usually leads to a handful of patents each having the largest possible scope of protection of an invention having market potential. Discount IPM, however, leads to a higher number of patents each having a lower scope of protection of an invention with questionable market potential.

Figure 1 shows a portfolio of patents according to Discount IPM. The dashed line separates the market potential domain on the right hand side from the domain comprising patents having no market potential ("waste domain") on the left hand side. That is, only patents in the market potential domain are directed to inventions which are relevant to the market. The main circle defines the patent portfolio of the enterprise. Each smaller circle within the main circle defines one patent. The size of the circle of each patent is proportional to the size of protective scope of each patent.

Thus, application of Discount IPM indeed has the advantage of obtaining a large number of patents at calculable cost, however at the expense of the scope of protection and the market relevance of the underlying invention.

Lean IPM avoids the creation of patents within the waste domain and focuses on patents having a large scope of protection within the market potential domain [9]. Such a patent portfolio is shown in Figure 2.

The dashed line in Figure 2 separates the market potential domain on the right hand side from the domain comprising patents having no market potential ("waste domain") on the left hand side. As can be seen from Figure 2 no patents are present in the waste domain, since these patents are avoided by applying Lean IPM. Applying Lean IPM leads to patents in the market potential domain only. 


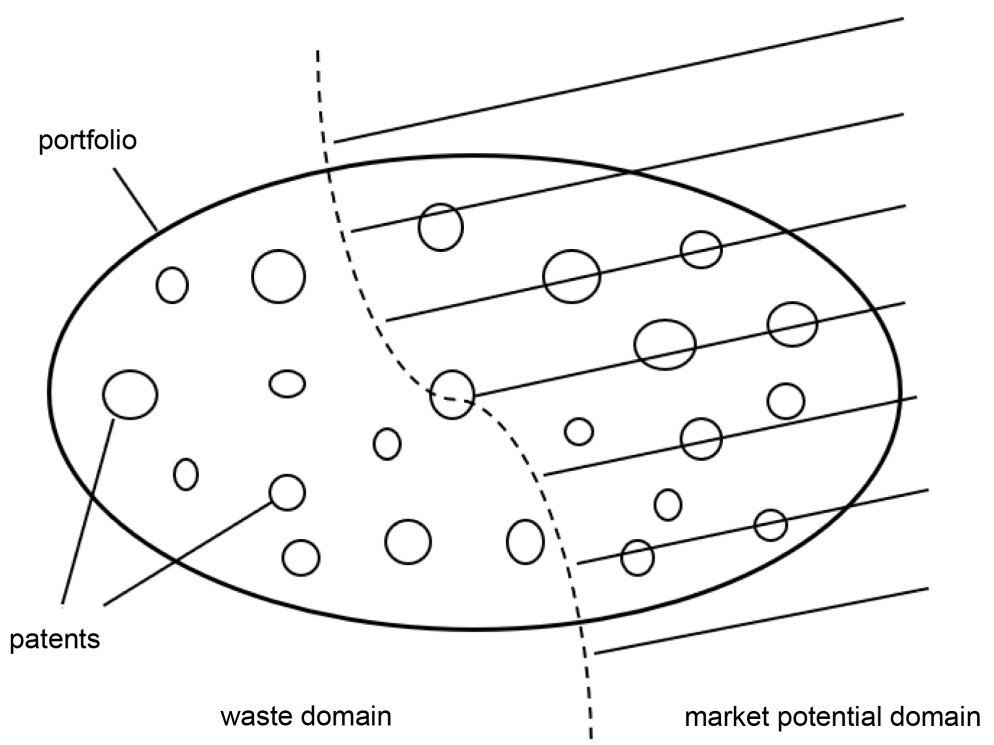

Figure 1. Patent portfolio when applying discount IPM.

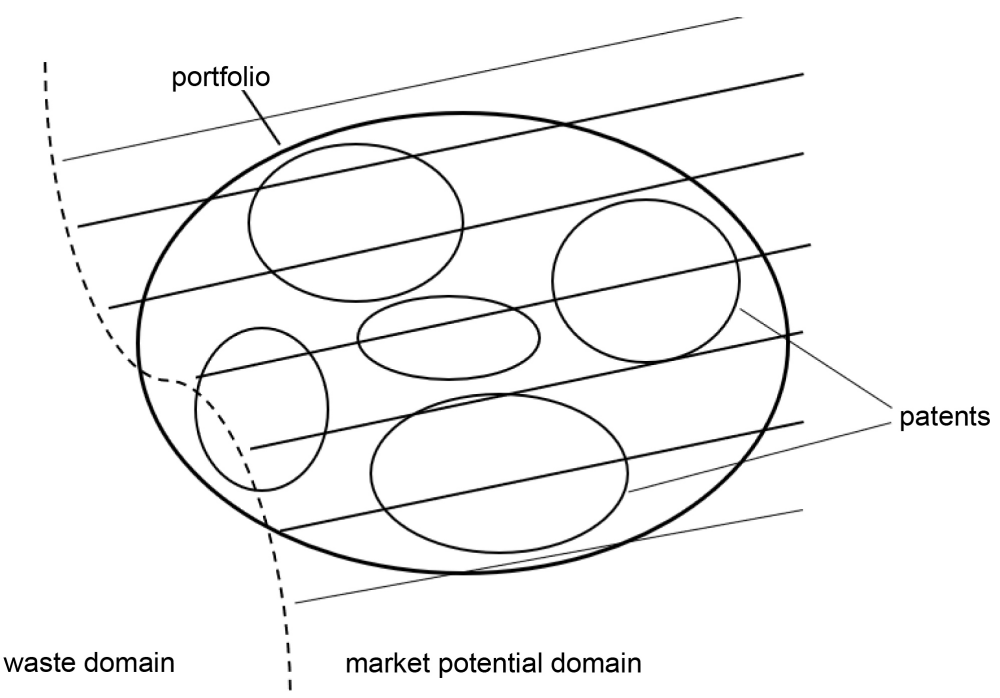

Figure 2. Patent portfolio when applying lean IPM.

That is, the costs for a large number of patents are avoided, since only a handful of patents are obtained protecting inventions having market potential.

\section{Conclusions}

While discount IP Management focuses on the economic management of a large number of patents, Lean IP Management focuses on a handful of valuable patents. Discount IP Management primarily looks at how many patents can be handled cost-effectively. Here, it is important how a large patent portfolio can be obtained at a low cost, with a reduction in patent quality taken into account.

Lean IP Management is concerned solely with valuable high-quality patents, which always goes hand in hand with economic benefit. Lean IPM focuses only on the economic benefit and positive-asset creation of an enterprise. Under the 
Lean IPM doctrine, useless patents are eliminated and creating new useless patents is avoided. In return, the creation of useful patents is greatly demanded since positive assets lead to economic benefit. The more resources are saved by eliminating and avoiding useless patents, the more resources can be invested into useful patents, thereby generating financial value. According to Lean IPM, patent applications are concisely drafted to focus on assigning protective rights solely to features of an invention where there is strong market potential [3]; features or definitions lacking market potential are omitted. In doing so, the quality of patents automatically increases. That is, by following LIPM's core "less is more" approach a company can slash its IP rights expenses. Saving costs for patents while increasing their quality will always go hand in hand with economic benefit for an enterprise.

\section{Conflicts of Interest}

The authors declare no conflicts of interest regarding the publication of this paper.

\section{References}

[1] Baldus, O., Dübon, P. and Barth, M. (2018) On the Value of Patents in Lean IP Management. American Journal of Industrial and Business Management, 8, 1113-1122. https://doi.org/10.4236/ajibm.2018.85077

[2] Mittelstaedt, A. (2016) Intellectual Property Management. Springer Gabler, Wiesbaden, p. 96. https://doi.org/10.1007/978-3-658-02992-0

[3] Bartenbach, K. and Volz, F.-E. (2013) Arbeitnehmererfindungsgesetz(ArbEG). Carl Heymanns, Cologne, p. 952

[4] Baldus O., Barth, M. and Heckmann, C. (2019) Lean Applications for Lean IP Management. Journal of Intellectual Property Law \& Practice, 14, 93-98. https://doi.org/10.1093/jiplp/jpy165

[5] Zipf, G.F. (1949) Human Behavior and the Principle of Least Effort. An Introduction to Human Ecology. Addison-Wesley Press, Cambridge, Mass.

[6] Akerlof, G.A. (1970) The Market for Lemons: Quality Uncertainty and the Market Mechanism. The Quarterly Journal of Economics, 84, 488-500. https://doi.org/10.2307/1879431

[7] Porter, M.E. (1980) Competitive Strategy. Free Press, Hong Kong.

[8] Porter, M.E. (1985) Competitive Advantage. Free Press, Hong Kong.

[9] Baldus O. and Heckmann, C. (2017) Lean IP-Management-Saving Costs for IP Management on a Paradigm Change in Assessing Inventions. American Journal of Industrial and Business Management, 7, 760-770.

https://doi.org/10.4236/ajibm.2017.76054 